
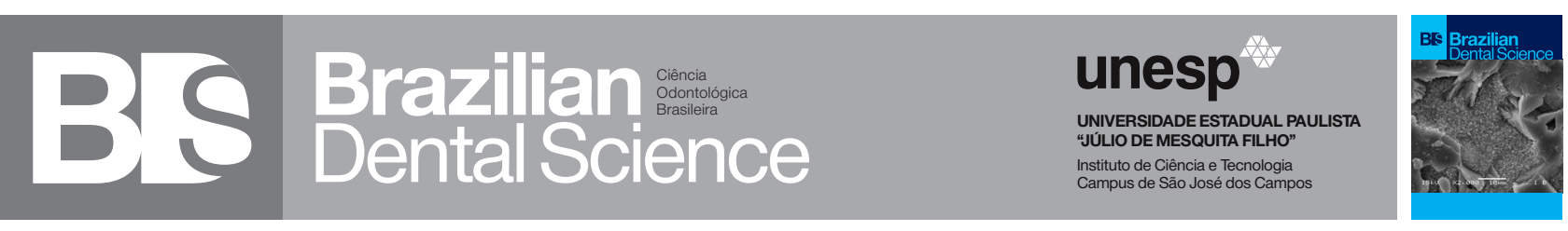

\title{
Color assessment in dental prostheses: the use of smartphones as process tools
}

\author{
Tomada de cor em prótese dentária: Uso de celular como auxílio do processo
}

Charles Jourdan ALBERT ${ }^{1}$, Elielson Nobrega da SILVA ${ }^{1}$, Marcela Moreira PENTEADO ${ }^{1}$, Dimas Renó de LIMA ${ }^{1}$, Estevão Tomomitsu KIMPARA $^{1}$, Eduardo Shigueyuki UEMURA ${ }^{1}$

1 - São Paulo State University (Unesp) - Institute of Science and Technology, São José dos Campos - SP - Brazil.

\begin{abstract}
Accurate color selection of direct or indirect dental restorations is a subjective task. Mobile phones are tools that may minimize color assessment errors. The objective was to use photographs taken with smartphones to guide the dental surgeon in choosing the right color in oral rehabilitation. A tooth was photographed for color assessment and the VITA Toothguide 3D-MASTER® shade guide was used. Photographs were submitted to an image editing software for full saturation removal. Images of the tooth and scale in black and white were compared. This method allowed to select the tooth's value, which is considered the most subjective dimension in color choice. Although it is an auxiliary and complementary method to traditional methods, smartphones are tools capable of reducing the range of color possibilities and minimizing possible failures.
\end{abstract}

\section{KEYWORDS}

Color; Photograph; Smartphone.

\section{RESUMO}

A correta seleção da cor das restaurações dentais diretas ou indiretas é uma atividade subjetiva. Os celulares são ferramentas que podem minimizar os erros da tomada de cor. O objetivo foi utilizar fotografias realizadas com smartphones para orientar o cirurgião-dentista na escolha da cor em reabilitação oral. Foi fotografado um dente para tomada de cor e a escala Vita 3D Master. As imagens foram submetidas a um software de edição de imagem para remoção total da saturação. As imagens em preto e branco do dente e da escala foram comparadas. A metodologia permitiu selecionar o valor do dente que é o aspecto considerado mais subjetivo na escolha da cor. Apesar de ser um método auxiliar e complementar aos métodos tradicionais é uma ferramenta capaz de diminuir o leque de possibilidades de cores e minimizar possíveis falhas.

\section{PALAVRAS-CHAVE}

Cor; Fotografia; Celular.

\section{INTRODUCTION}

R egarding dental esthetics, the most 1 noticeable aspect in a smile is the color of the teeth [1]. Effective assessment and color communication in prosthetic restorations containing adjacent teeth as reference are very important steps for successful rehabilitation $[2,3]$. Color choice, nonetheless, is a subjective task that may be influenced by lighting conditions and the visual acuity of each professional [1].
There is also a lack of standardization across different scale systems and corresponding ceramic systems in the industry. Additionally, the highly complex nature of the color distribution within a single tooth, as well as shape, surface texture, and brightness, all affect the accurate perception of colors [3-6].

Preston's classical color choice technique indicates the use of a standardized scale for comparison with the tooth, under natural light 
and quickly through the initial $5 \mathrm{~s}$ of visualization, as the first impressions are the most accurate [7]. In this way, three aspects are considered: value, hue and chroma (Munsell System).

Hue is the name or description of a color, and refers to the quality by which a family of color is differentiated from another, as in the case of yellow, blue, green. Value, on the other hand, may be considered the most important dimension for the dental surgeon, as it corresponds to intensity and brightness. It is an achromatic property, with no hue whatsoever, that represents the amount of white (opacity) and gray (translucency) [5]. A higher value represents greater opacity and a larger amount of white, hence a lighter tooth. When the tooth is darker, it has higher translucency, larger amount of gray and, consequently, a lower value. Failure in assessing the value, therefore, may result in whitish or greyish restorations. The applicability of this dimension assertively in terms of light reflection is what makes a restoration seem more natural [8].

Finally, chroma refers to the strength or dominance of hue, i.e. saturation. In clinical practice it is observed that teeth have higher chroma in the cervical region, while incisal regions present lower chroma [9]. Although these concepts are well-defined, color choice is still considered subjective [10], may be improved in time, as clinical experience increases [11], and value is usually the dimension that causes the most doubts upon choice.

Elicited by both technological growth and reduction in the costs associated with digital photo equipment, photographic documentation has ceased to be restricted to a few dentists only, and has become the routine for many professionals [12], as it assists in analyzing patients' esthetic details with ease, including shade matching [13], without the need for a faceto-face assessment, in addition to optimizing both the design of an initial treatment plan and the communication with the patient.

With the greater acess to smarthphones, new strategies of treatment are releasing. There is reports of this use to motivation training of brushing teeth by app [14], to instructions of the use of orthodontics appliances by games [15], to assessment of occlusal caries by photos [16] or even to teach the emergency management of avulsed teeth [17].

Ivoclar Vivadent provides a free app (IPSe. max Shade navigation app) to direct the ceramic collor choice to indirects restorations. Through 5 steps, the professional fund the app with informations by the tooth related to initial collor after prepar, recommended treatment, collor of the dentin, thickness of the prepar and the kind of ceramics would like to use. The results are an option of collor blocks that manufacturer provide to obtain the esthetic final desired restoration.

Considering the matching shade with professional digital cameras $[13,14]$ and the evolution of the digital cameras in mobile (smart) phones, the photographic process has been simplified, allowing visualization and transmission of images in real time. Nevertheless, it is extremely important to define a standardized protocol for photographs. There are several types of protocols suggested in the literature, but the ideal protocol is one that best suits the needs of the professional and the patient, according to the procedure type that will be carried out. The purpose of this work is to provide a simple and specific protocol for color assessment through smartphones. The null hypothesis is that digital photographs from smartphones are able to properly indicate the value of a natural tooth.

\section{CASE REPORT}

The VITA Toothguide 3D-MASTER $\AA$ (Vita Zahnfabrik, Bad Sackingen, Germany) dental shade guide, which has been reported to be reliable for instrumental analysis shade 
guide is the most suited for using as a color reference [12], since its value varies from left to right, i.e. from highest to lowest, and is divided into groups according to these values (Figure 1). A photograph of this shade guide was taken through a smartphone camera using natural light at the morning day.

A voluntary patient was subjected to dental prophylaxis. Then her smile with the shade guide close to the teeth was also photographed with the same device at $14 \mathrm{~cm}$ of distance and angle of $90^{\circ}$ between the smartphone and the patient's smile [20], using natural light at the morning day (Figure 2).

In order to choose the value, the photograph went through an image edition application, available on the smartphone itself, in order to completely remove the saturation (hue and chroma). The final result is a black and white photograph, where only the value is observed (Figure 3). The removal of saturation may also be achieved through the smartphone camera's native application (Figure 4). Some devices provide a monochromatic mode/ filter before capturing the image. Then, the smile photograph is compared to the color scale photo.

After adequate selection of the value, the choices for hue and chroma were made, which became easier and more precise, since the number of options was reduced simply by the definition of the value. The figure 5 shows a protocol step by step to choice de color: 1) Get the scale and smile photo with smartphone; 2) Create the scale and smile monochromatic photos; 3) Compare images scale and tooth; 4) Definition of value; 5) Choice of hue; 6) Choice of Chroma; 7) Get the tooth color.

The spectrophotometer Easyshade (Vita Zahnfabrik, Bad Sackingen, Germany) was used like a color control [6] and it was check the tooth and scale colors, according to the manufacturer's guidance (Figure 6).

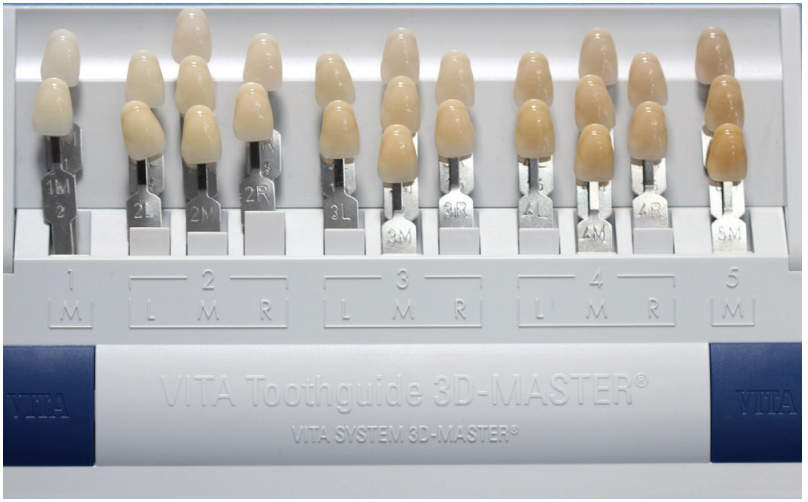

Figure 1 - VITA Toothguide 3D-MASTER ${ }^{\circledR}$ shade guide.

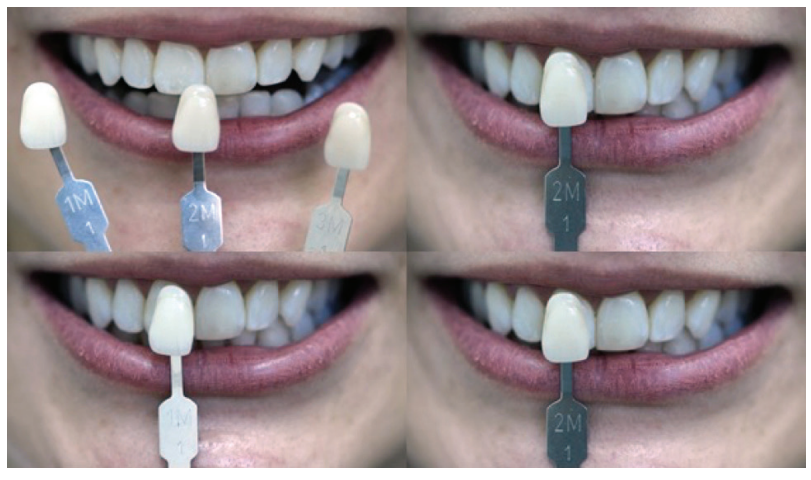

Figure 2 - Initial smile image of the patient, with 3 color options positioned.

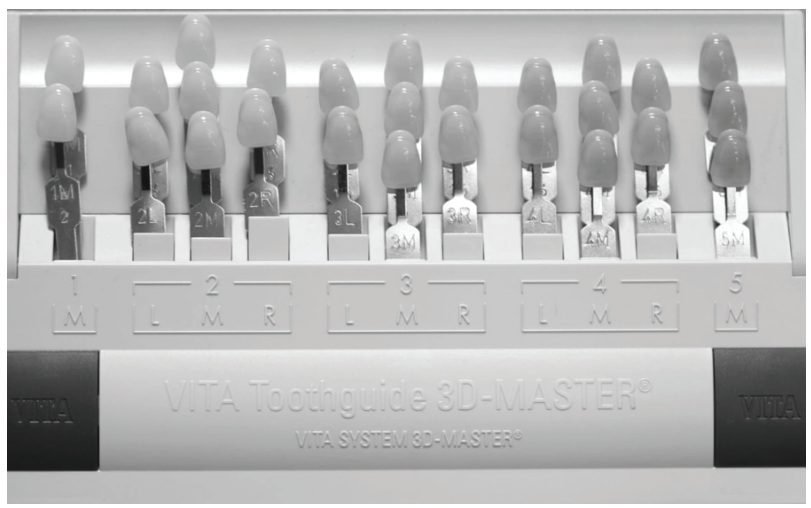

Figure 3 - Monochromatic image showing all different values in the VITA Toothguide 3D-MASTER ${ }^{\circledR}$ shade guide. 


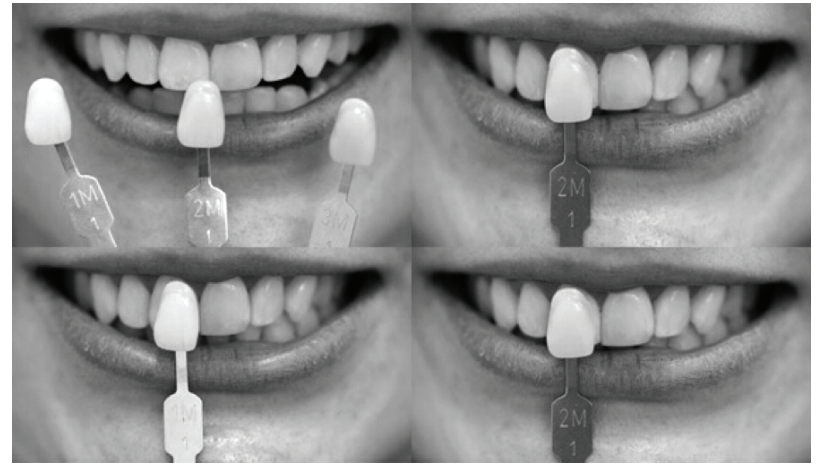

Figure 4 - Comparison among the values of the 3 selected scale options with the tooth.

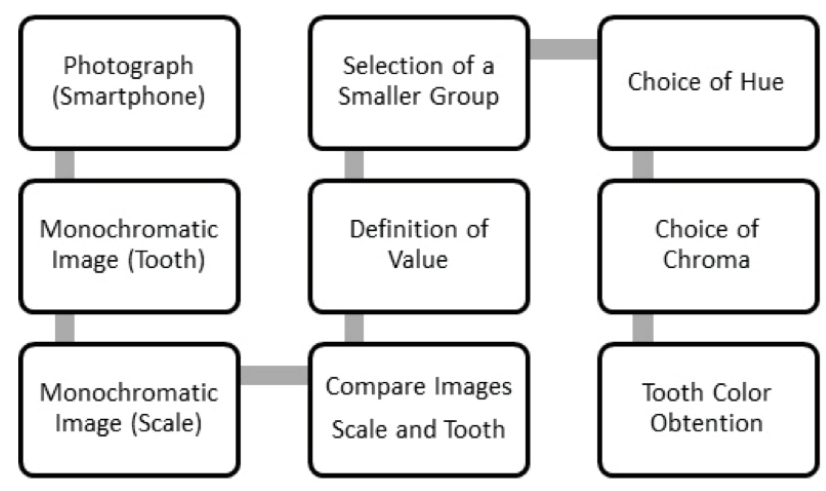

Figure 5 - Protocol for smartphone use, value definition, and choice of the final color.

\section{RESULTS}

Figure 4 shows the difference between grayscale options in the standardized color scale and the patient's natural tooth. This simple picture has made it possible to set parameter number 3 as the value. Among the range of options for parameter \#3 (L, M, R for hue and $1,2,3$ for chroma), the final color $3 \mathrm{M} 1$ was chosen. This information was sent directly to the lab, along with the colored and black and white photographs, using the WhatsApp application. The results of spectrophotometer were 3M1 to the tooth and the scale (Figure 7) and it's the same color chosen by the smartphone protocol. Then, the expert evaluation of the technician rendered agreement in the color choice.

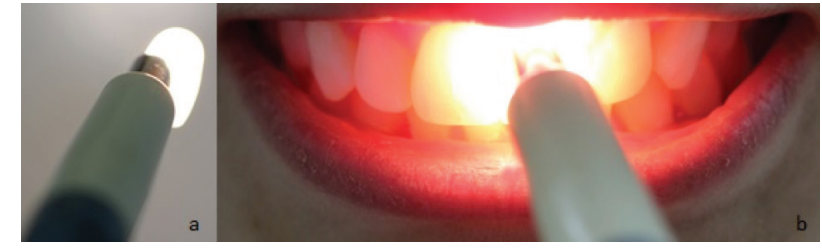

Figure 6 - Use of spectrophotometer Easyshade at the color scale(a) and at the patient (b).

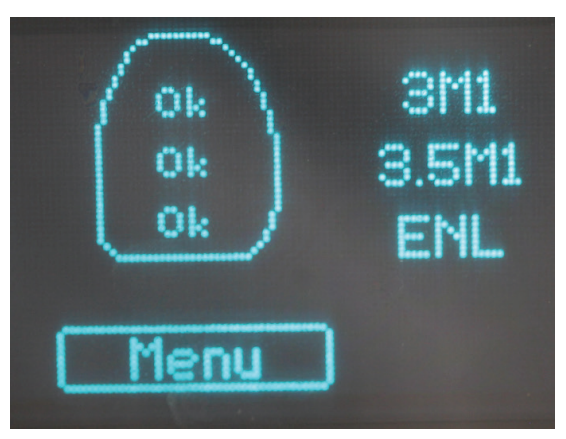

Figure 7 - Results of spectrophotometer to the tooth and the scale. Both of them were 3M1.

\section{DISCUSSION}

The null hypothesis that digital photographs made by smartphones are able to properly indicate the value of a natural tooth was accepted for this study.

A wide range of digital devices for tone analysis such as spectrophotometers, colorimeters, scanners and other software are available on the market today [21-23]. However, these usually incur additional costs to perform the procedure and training to handle the device [23]. Currently, smartphones are efficient when it comes to photography, and their cameras are capable of generating good images with greater ease. The existence of several communication features such as Wi-Fi, Bluetooth, mobile internet access (4G), and a wide range of image editing applications such as the Camera+ app (available for iOS and Android platforms) provides great control over many parameters of image capture in the smartphone camera, including aperture settings, exposure speed, white balance, and ISO. Additionally, there is the possibility of using external lenses that may be coupled to the smartphone, so that images with macro function can be taken. Furthermore, after the image is generated it is possible to immediately forward it to the laboratory through applications, 
which greatly facilitates the dentist-laboratory communication, and consequently simplifies case planning.

Among the various possibilities of using a smartphone to choose the color, the selection of the value generates great interest, since it is an aspect that raises doubts during the procedure, and its definition considerably restricts the final color options.

When taking photographs for this use, care should be taken with brightness, adequate removal of lips and cheeks with the use of retractors, as well as backgrounds, in order to eliminate unwanted structures and emphasize the main subject of photography [4].

\section{CONCLUSIONS}

It concluded that:

- The use of smartphones for dental imaging is a simple and effective complementary method for choosing color in oral rehabilitations.

- It is an access tool that allows immediate communication with the laboratory.

- Rehabilitations with prostheses may be optimized for color choice with the use of smartphones.

\section{REFERENCES}

1. DraghiciR,PreoteasaCT, Tâncu AMC,PreoteasaE.Dental color assessment through TTBexercises. JMed Life.2016 Jan-Mar;9(1):61-65.

2 FondriestJ.Shadematching in restorative dentistry: the science and strategies. IntJ Periodontics RestorativeDent.20030ct,23(5):467-79.

3. Brewer JD, Wee A, Seghi R.Advances in color matching.DentClin North Am.2004 Apr:48(2):v,341-58

4. McLarenEA, TerryDA. Photography in dentistry.JCalifDentAssoc. 2001 0ct:29(10):735-42

5. ChuSJ,DevigusA,Mieleszko AJ.TheFundamentals of Color:Shade Matching and Communication inEsthetic Dentistry.Chicago,IL:Quintessence Publishing;2004
6. FaziG VichiA CorciolaniG,FerrariM. Spectrophotometrice valuation of color match to VITA classical shade guide of four different veneering porcelain systems for metal ceramic restorations. Am JDent 2009Feb;22(1):19-22

7. ChaHS,Lee YK.Difference in illuminant dependent color changes of shade guide tabs by the shade designation relative to three illuminants. Am JDent2009 Dec;22(6):350-6.

8. AhnJS,Lee YK.Color distribution of a shade guide in the value, chroma, and hue scale.JProsthetDent.2008Jul;100(1):18-28.doi:101016/S0022-3913(08)60129-8.

9. BurkinshawSM. Colour in relation to dentistry.Fundamentals of color science. Br DentJ.2004Jan 10;196(1):33-41;discussion29.

10. Imbery TA, GeissbergerM,HakimF,Al-Anexi S,Uram-TuculescuS, GottliebR, Estrich CG. Evaluation of four dental clinical spectrophotometers relative to human shade observation.JAmDentAssoc.2013;144(10):1183-6. doi:10.14219/jada. archive.2013.0041.Epub2014Dec 19.

11. Joiner A. Tooth colour:areview of the literature.JDent.2004;32Suppl 1:3-12

12. McLarenEA.Shade Analysis and Communication:2010. Inside Dent [Internet] 2010:6(5)58-66. Avaiableat:https:/wwwwaegisdentalnetwork.com/id/2010/05/ shade-analysis-and-communication-2010.

13. TamWK,LeeHJ.Dental shade matching using a digital camera JDent2012 Dec;40 Suppl2:e3-10. doi: 10.1016/j.jdent201206.004. Epub2012Jun17.

14. Brokos $Y$,Stavridakis M,Krejcil.A novel method of capturing fluorescence in clinical dentistry.Compend ContinEduc Dent.2018Jan;39(1):e1-e4.

15. ChaudhariP,Hotwani K, SharmaK, Nagpal D, Lamba G. Smartphones and tooth brusing: content analysis of the current available mobile health apps for motivation and training. Eur Arch Paediatr Dent.2019 Jun 1. doi: 10.1007/s40368-019-00457-1. [Epubahead of print]

16. SiddiquiNR,Hodges S, Sharif MO. Availability of orthodontic smartphone apps. $J$ Orthod.2019Sep;46(3):235-241.doi:10.1177/1465312519851183. Epub2019 Jun6.

17. EstaiM,Kanagasingam Y,HuangB,ShiikhaJ,KrugerE,BuntS, etal.Comparion of a Smarthphone-Based Photographic Method with face-to-face caries assessment: amobile teledentistry model. TelemedJEHealth.2017 May,23(5):435-440. doi: 10.1089/tmj:2016.0122.Epub2016 Nov17.

18. Al-MusawiA,Al-SaneM,Andersson LSmartphone Appasanaid in the emergencymanagement of avulsed teeth.Dent Traumatol.2017Feb;33(1):13-18. doi:10.1111/edt12298. Epub2016 Aug31.

19. CorciolaniG,Vichi A, GoracciC,Ferrari M.Colour correspondence of a ceramic system in two diferente shade guides.JDent2009Feb;37(2):98-101. doi: 10.1016/] jdent2008.10.001. Epub2008Nov8.

20. LeeHJ,Tam WK. Accurate shade image matching by using a smartphonecâmera JProsthodontRes. 2017 Apr;61(2):168-176. doi:10.1016/j.jpor2016.07.004. Epub2016 Aug20.

21. ChuSJ, Trushkowsky RD,ParavinaRD.Dental color matching instruments and systems. Review of clinical and research aspects.J Jent 2010;38Suppl2:e2-16. doi: 10.1016/j.jdent2010.07.001. Epub2010 Aug1.

22 Yuan JCC,Brewer JD,MonacoEAJ,DavisEL Defining anatural tooth color space basedona3-dimensional shade system.JProsthetDent2007 Aug:98(2):110-9.

23. Carney W,JohnstonM. The development of a novel shade selection program for fixed shade translucent dental materials.J Dent.2017 Jul,62:81-84. doi:10.1016/j. jdent2017.05.002.Epub2017 May 16.

\section{Marcela Moreira Penteado} (Corresponding address)

Av. Eng. Francisco José Longo, 777 - Jardim São Dimas - São José dos Campos/SP - CEP 12245-00

E-mail: dramarcelamoreira@hotmail.com

Date submitted: 2019 Fev 21 Accept submission: 2019 Aug 06 